\title{
Pengaruh Bauran Promosi Terhadap Keputusan Pembelian Kamar Oleh Tamu di UNP Hotel \& Convention Kota Padang Ovrio Yusmar ${ }^{1}$,Hijriyantomi Suyuthie ${ }^{2}$ \\ ${ }^{1}$ Universitas Negeri Padang \\ ${ }^{2}$ Universitas Negeri Padang \\ e-mail: ovrioy@gmail.com, hsuyuthie@fpp.unp.ac.id
}

\begin{abstract}
Abstrak
Penelitian ini di latar belakangi oleh permasalahan dimana promosi merupakan bagian penting di pemasaran dengan tujuan penelitian melihat pengaruh promotion mix terhadap keputusan konsumen dalam membeli kamar pada UNP Hotel \& Convention Padang, penelitian ini menggunakan metode asosiatif kausal. Sampel yang digunakan merupakan tamu yang pernah menginap dan sedang menginap di UNP Hotel \& Convention Padang yaitu berjumlah 88 orang tamu dengan teknik probability sample. Teknik pengumpulan data menggunakan cara menyebarkan kuesioner dengan dua puluh lima butir pernyataan, sepuluh butir pernyataan untuk bauran promosi dan lima belas pernyataan untuk keputusan pembelian kamar. Selanjutnya data dideskripsikan serta dikakukan uji persyaratan analisis dan uji hipotesis menggunakan regresi linear sederhana dan koefisien determinasi dengan SPSS versi 22.00. Dari hasil pengujian hipotesis, didapatkan nilai R Square dengan angka 0,262 yang artinya pengaruh untuk variabel $(\mathrm{X})$ bauran promosi dan variabel $(\mathrm{Y})$ dimana keputusan pembelian kamar dengan angka 26,2\% dan selanjutnya 73,8\% dikarenakan faktor lain. Maka didapat koefisien regresi dengan angka 0,928 nilai signifikannya adalah $0,000<0,5$. Dapat diartikan dalam tingkatan angka 1 satuan bauran promosi mengalami peningkatan 0,928 pada keputusan pembelian kamar. Jadi hipotesisnya adalah $\mathrm{Ha}$ diterima dan Ho ditolak.
\end{abstract}

\section{Kata Kunci :Bauran Promosi, Keputusan Pembelian Kamar.}




\section{PENDAHULUAN}

Persaingan bisnis hotel bukan hanya persaingan dari segi fasilitas bentuk seperti kamar, namun aspek promotion juga menjadi salah satu strategi yang ampuh dalam persaingan business perhotelan. Aspek promotion merupakan hal utama, termasuk halnya dengan memperhatikan bauran promosi. Promosi merupakan hal penting bagi pemasaran, yang berarti seberapa besar pun manfaat sebuah product jika product tersebut tidak diketahui oleh konsumen maka product tersebut tidak akan diketahui manfaatnya [1]. Aspek promotion bertujuan untuk menyampaikan information kepada penjual dan pembeli dengan cara menyebarkan information, affect, and consumer appeal untuk membeli barang atau jasa yang ditawarkan oleh company or business. Pada aspek promotion terdapat promotion mix yang bertujuan untuk need recognition agar konsumen memahami produk dan jasa yang ditawarkan.

UNP Hotel \& Convention Padang merupakan hotel bintang 3 di kota Padang, berlokasi di area sekitaran Universitas Negeri Padang. UNP Hotel \& Convention Padang memiliki 6 tipe kamar diantaranya : Strandart Room, Superior Twin, Deluxe Room, Family Executive, Bussines Room, dan Suite Room, Serta memiliki 4 Meeting Room dan 1 ballroom, dan juga terdapat fasilitas penunjang seperti SPA dan Retaurant.

Keputusan pembelian merupakan pengintegrasian dalam mengkombinasikan pengetahuan dua atau lebih prilaku alternatif serta memilih diantaranya [2]. Occupancy suatu hotel dilihat dari banyaknya tingkat hunian kamar. Banyak faktor yang mempengaruhi keputusan tamu dalam menginap, salah satunya dari faktor pemasaran atau faktor dari perilaku konsumen itu sendiri. Dalam mempengaruhi tingkat occupancy strategi penjualan yang di lakukan oleh hotel juga merupakan faktor penentu. Kegiatan pemasaran ini bertujuan untuk mempengaruhi konsumen atau calon konsumen agar barang atau jasa hotel yang tersedia dapat dimanfaatkan langsung oleh konsumen.

Promosi merupakan aktifitas komunikasi, dimana keputusan tamu dalam memilih tempat menginap dapat dipengaruhi oleh faktor promosi [3]. Agar konsumen dapat menetapkan kegiatan dalam proses pembelian dengan tepat, hotel perlu mempelajari dan memahami perilaku konsumen sebelum kegiatan promosi dilakukan. Mempengaruhi konsumen atau calon konsumen supaya membeli barang atau jasa dari hotel adalah beberapa tujuan dari kegiatan promosi. Perusahaan-perusahaan biasanya bersaing dengan konsep bauran promosinya.

Dalam hal ini UNP Hotel \& Convention Padang harus meningkatkan strategi promosinya. Menurut Kotler [4] ada lima bauran promosi secara umum terdiri dari : advertising, sales promotion, personal selling, pubic relations, direct marketing. Pengaruh promotion terhadap keputusan pembelian menjelaskan bahwa semakin tinggi dan menariknya promotion yang dilakukan oleh perusahaan, maka semakin tinggi keinginan konsumen untuk melakukan pembelian pada produk atau jasa tersebut. Walaupun adakalanya promosi bukanlah sebagai faktor penentu dalam mempengaruhi konsumen untuk menginap di suatu hotel [5]. Promosi lebih kepada cara hotel mengkomunikasikan produk yang di tawarkan.

Berdasarkan hasil pra penelitian, ditemui beberapa masalah adanya tingkat hunian kamar atau occupancy di UNP Hotel \& Convention Padang cenderung tidak stabil dan tidak semua bauran promosi yang dilakukan UNP Hotel \& Convention Padang mampu menarik konsumen untuk memberikan keputusan pembelian kamar di UNP Hotel \& Convention Padang,kemudian tidak banyaknya pemanfaatan media pendukung dalam kegiatan promosi seperti penggunaan katalog dan brosur, kurangnya jumlah karyawan pada departmen sales \& marketing di UNP Hotel \& Convention Padang sehingga promosi tidak optimal, UNP hotel belum memiliki atau menglola website sendiri sehingga promosi yang dilakukan belum 
efektif. Pentingnya penelitian ini penulis lakukan adalah agar pihak hotel dapat meningkatkan lagi promosinya supaya occupancy naik dan stabil.

\section{METODOLOGI PENELITIAN}

Penelitian ini menjadi penelitian kuantitatif dengan pendekatan asosiatif kausal dan menggunakan metode survey berupa kuesioner yang disebarkan kepada sample untuk diisi. Jenis teknik dalam menentukan banyak sampel ini menggunakan teknik probability sampling [6]. Didapatkan jumlah 88 orang untuk total responden yang diakui sudah representatif karena jumlah sampel lebih dari batas minimal yaitu sebanyak 30 responden. Pengumpulan data menggunakan kuesioner dengan menggunakan lima pilihan jawaban, yang telah melalui uji validitas dan reliabilitas. Pengujian hipotesis menggunakan analisis regresi linear yang dibantu dengan menggunakan SPSS 20.00, dalam menentukan besar pengaruh antar variabel.

\section{HASIL DAN PEMBAHASAN}

Berdasarkan deskripsi data untuk variabel (X) bauran promosi, berupa kuesioner yang disusun dengan pernyataan yang telah diuji validitas serta reliabilitasnya yang kemudian disebar kepada 88 responden untuk diberi jawaban. Jumlah soal yang diberikan sejumlahsepuluh butir yang diisi oleh sejumlah responden. Selanjutnya, hasil yang didapatkan dari penelitian dalam hal bauran promosi di UNP Hotel \& Convention Padang adalah sebagai berikut :

Tabel 1. Data Variabel Bauran Promosi

\begin{tabular}{|c|c|c|c|}
\hline Category & Kelas Interval & Frequency & $\mathbf{( \% )}$ \\
\hline Sangat baik & $\geq 39,9$ & 8 & $9 \%$ \\
\hline Baik & $33,3-<39,9$ & 26 & $29 \%$ \\
\hline Cukup & $\mathbf{2 6 , 7}-<\mathbf{3 3 , 3}$ & $\mathbf{4 0}$ & $\mathbf{4 5 \%}$ \\
\hline Tidak baik & $20,1-<26,7$ & 14 & $16 \%$ \\
\hline Sangat tidak baik & $<20,1$ & - & - \\
\hline \multicolumn{2}{|r|}{ Total } & 88 & $100 \%$ \\
\hline
\end{tabular}

Berdasarkan hasil dari tabel diatas dijelaskan bahwa: 9\% menyatakan sangat baik, 29\% menyatakan baik, 45\% menyatakan Cukup, $16 \%$ menyatakan tidak baik, dan $0 \%$ untuk kategori sangat tidak baik. Maka kesimpulannya penelitian tamu dalam hal bauran promosi di UNP Hotel \& Convention Padang dikategorikan Cukup.

Selanjutnya untuk hasil uji pada variabel (Y) keputusan pembelian, dengan kuesioner yang berisikan lima belas butir pernyataan yang telah diuji validitasnya yang kemudian diisi oleh 88 orang responden. Maka didapatkan hasl sebagai berikut :

Tabel 2. Data variabel Keputusan Pembelian Kamar

\begin{tabular}{|c|c|c|c|}
\hline Categories & Interval Class & Frequency & $(\mathbf{\%})$ \\
\hline Sangat baik & $\geq 60$ & 18 & $20 \%$ \\
\hline Baik & $50-<60$ & 23 & $26 \%$ \\
\hline Cukup & $\mathbf{4 0}-<\mathbf{5 0}$ & $\mathbf{3 6}$ & $\mathbf{4 1 \%}$ \\
\hline Tidak baik & $30-<40$ & 12 & $12 \%$ \\
\hline Sangat tidak baik & $<30$ & $\mathrm{I}$ & $\mathrm{I} \%$ \\
\hline \multicolumn{2}{|r|}{ Jumlah } & 88 & $100 \%$ \\
\hline
\end{tabular}


Pada table diatas dijelaskan bahwa variabel Keputusan pembelian kamar sebanyak 20\% responden termasuk dalam category sangat baik, $26 \%$ responden termasuk dalam kategori baik, $41 \%$ responden termasuk dalam kategori cukup, $12 \%$ responden dalam kategori tidak baik, dan $1 \%$ termasuk kategori sangat tidak baik.

\begin{tabular}{|c|c|c|c|c|c|c|}
\hline Model & & $\begin{array}{l}\text { Sum of } \\
\text { Squares }\end{array}$ & Df & Mean Square & $F$ & Sig. \\
\hline \multirow{3}{*}{1} & Regression & 2366.607 & 1 & 2366.607 & 30.508 & $.000^{\mathrm{b}}$ \\
\hline & Residual & 6671.382 & 86 & 77.574 & & \\
\hline & Total & 9037.989 & 87 & & & \\
\hline
\end{tabular}

Berdasarkan pada pengujian hipotesis didapatkan nilai Frekuensi 30.508, sign 0,000 < 0,05 dijelaskan bahwa variabel bauran promosi berdampak secara signifikan kepada variabel keputusan pembelian, maka $\mathrm{Ha}$ diterima dan Ho ditolak.

Tabel 4. Koefisien Regresi Variabel X Terhadap Variabel Y

\begin{tabular}{|c|c|c|c|c|c|}
\hline \multirow[t]{2}{*}{ Model } & \multicolumn{2}{|c|}{ Unstandardized Coefficients } & \multirow{2}{*}{$\begin{array}{l}\text { Standardized } \\
\text { Coefficients } \\
\text { Beta }\end{array}$} & \multirow[t]{2}{*}{$\mathrm{t}$} & \multirow[t]{2}{*}{ Sig. } \\
\hline & $\mathrm{B}$ & Std. Error & & & \\
\hline (Constant) & 20.777 & 5.465 & & 3.802 & .000 \\
\hline BauranPromosi & .928 & .168 & .512 & 5.523 & .000 \\
\hline
\end{tabular}

Berdasarkan persamaan diatas diperoleh koefisien regresi sebesar 0.928 dengan nilai Sig $0.000<0.05$. Artinya setiap peningkatan sebesar 1 satuan bauran promosi akan meningkatkan 0.928 satuan keputusan pembelian kamar.

Tabel 5. Hasil Test $\mathrm{R}$ Square Variabel $\mathrm{X}$ dan $\mathrm{Y}$

\begin{tabular}{|l|l|l|l|l|}
\hline Model & $R$ & $R$ Square & $\begin{array}{l}\text { Adjusted } \\
\text { Square }\end{array}$ & $\begin{array}{l}\text { Std. Error of the } \\
\text { Estlmate }\end{array}$ \\
\hline $\mathrm{I}$ & $.512^{\mathrm{a}}$ & .262 & .253 & 8.808 \\
\hline
\end{tabular}

Berdasarkan dari hasil uji R Square $=0.262$ jadi pengaruh bauran promosi terhadap keputusan pembelian kamar adalah $26 \%$ sedangkan $74 \%$ ditentukan oleh faktor lain. 


\section{Pembahasan}

\section{Bauran Promosi (X)}

Bauran promosi $(\mathrm{X})$ dilihat dari 5 indikator yaitu : a) advertising (iklan) dengan persentase $37 \%$ termasuk dalam kategori cukup, berdasarkan data yang diperoleh dari tamu meliputi : UNP Hotel \& Convention Padang memiliki iklan dengan media elektronik yang menarik, UNP Hotel \& Convention Padang memiliki iklan dengn pamflet seperti brosur dan katalog yang menarik. b) personal selling ( penjualan tatap muka) dengan persentase $39 \%$ termasuk dalam kategori baik,berdasarkan data yang diperoleh dari tamu meliputi : UNP Hotel \& Convention Padang melakukan penjualan tatap muka dengan melakukan pendekatan ke instansi-instansi seperti PT Pos Indonesia, Kemenkum HAM dan lainnya. c) sales marketing (promosi penjualan) dengan persentase 35\% termasuk dalam kategori Cukup, berdasarkan data yang diperoleh dari tamu yang meliputi : UNP Hotel \& Convention Padang memberikan diskon kepada para tamu, UNP Hotel \& Convention Padang memberikan voucher menginap kepada para tamu. d) public relations \& publicity (masyarakat luas) dengan persentase $35 \%$ termasuk dalam kategori cukup, berdasarkan data yang diperoleh dari tamu yang meliputi : saya mendapatkan informasi tentang UNP Hotel \& Convention Padang dari pihak corporate (perusahaan) dan instansi-instansi yang bekerja sama denga hotel. Saya mendapatkan informasi tentang UNP Hotel \& Convention Padang dari pihak travel agent yang bekerja sama dengan hotel. e) direct marketing (pemasaran langsung) dengan persentase $43 \%$ termasuk dalam kategori baik, berdasarkan data yang diperoleh dari tamu meliputi : UNP Hotel \& Convention Padang mengirim e-mail kepada tamu dengan bahasa yang menarik, ketersediaan website UNP Hotel \& Convention Padang membantu saya untuk mengetahui tentang ketersediaan produk hotel, petugas reservasi hotel mampu menjawab setiap pertanyaan yang saya berikan.

Berdasarkan penjelasan diatas variabel bauran promosi di UNP Hotel \& Convention Padang berada pada kategori /cukup, dengan adanya penelitian ini diharapkan dapat menjadi gambaran atau masukan bagi perusahan atau hotel untuk meningkatkan bauran promosi dengan lebih baik lagi.

Artinya ialah penilaian tamu terhadap bauran promosi di UNP Hotel \& Convention Padang menyatakan cukup. Promosi dapat menginformasikan orang-orang tentang produk yang dihasilkan organisasi, individu maupun rumah tangga [7].

\section{Keputusan Pembelian (Y)}

Variabel keputusan pembelian (Y) dilihat dari 5 yaitu : a) need recognition (pengenalan kebutuhan) berada pada kategori Sangat baik dengan persentase $37 \%$, berdasarkan pernyataan yang diperoleh dari tamu meliputi : saya membutuhkan hotel sebagai tempat menginap bila berkunjung ke uatu daerah, saya membutuhkan hotel yang berada di lokasi strategis sebagai tempat menginap, saya membutuhkan hotel dengan promosi yang baik ebagai tempat menginap, pada saat melakukan perjalanan/berkunjung ke kota padang saya membutuhkan hotel sebagai tepat menginap. b) information search (pencarian kebutuhan) berada pada kategori Sangat Baik dengan persentase 32\% berdasarkan pernyataan yang diperoleh darai tamu : saya mendapatkan informasi mengenai UNP Hotel \& Convention Padang melalui teman, reka kerja dan keluarga, saya mendapatkan informasi megenai UNP Hotel \& Convention Padang melalui promosi yang dilakukan oleh pihak hotel, saya mengetahui informasi hotel dan mengetahui UNP Hotel \& Convention Padang adalah hotel dengan standar kualitas yang baik, saya mendapatkan informasi Hotel UNP \& Convetion Padang sesuai dengan yang dijelaskan di online travel agent yang dipilih. c) evaluation of alternative (evaluasi alternatif) berada pada kategori baik dengan persentase $34 \%$ berdasarkan pernyataan yang diperoleh dari tamu meliputi : saya merasa UNP Hotel \& Convention Padang 
mmemiliki harga kamar yang sebanding dengan fasilitas hotel, saya merasa UNP Hotel \& Convention Padang terletak dilokasi yang strategis, saya merasa UNP Hotel \& Convention Padang memiliki kualitas yang bagus sesuai dengan yang dijelaskan di online travel agent yang dipilih. d) purchase decision (keputusan pembelian) berada pada kategori sangat baik dengan persentase $34 \%$ berdasarkan pernyataan yang diperoleh dari tamu meliputi : saya memutuskan menginap di UNP Hotel \& Convention Padang karena percaya pada kualitas yang sesuai dengan kebutuhan dan keinginan saya, saya memilih menginap UNP Hotel \& Convention Padang karena informasi dari online travel agent yang saya pilih sesuai dengan apa yang diinginkan. e) postpurchase behavior (perilaku pasca pembelian) berada pada kategori cukup dengan persentase $37 \%$ berdasarkan data yang diperoleh dari tamu meliputi : saya merasa puas menginap di UNP Hotel \& Convention Padang, saya merekomendasikan kepada keluarga, teman, rekan kerja, untuk menginap di UNP Hotel \& Convention Padang

Artinya ialah penilaian tamu terhadap keputusan pembelian di UNP Hotel \& Convention Padang menyatakan kurang setuju. Menurut [8] keputusan pembelian dipengaruhi oleh kebiasaan pembelian dimana kapan waktunya pembelian dilakukan, dengan jumlah berapa pembelian dilakukan, dan dimana pembelian tersebut.

\section{Pengaruh Bauran Promosi terhadap Keputusan Pembelian}

Berdasarkan hasil test hipotesis yang dilakukan untuk mengetahui derajat pengaruh diantara bauran promosi terhadap purchase decision, unp hotel \& convention padang yang dibantu dengan SPSS version 22.00. Dalam penelitian ini hasil test Regresi linear sederhana diperoleh $\mathrm{F}$ hitung 30.508 dengan sign $0,000<0,05$ maka artinya variabel Bauran Promosi $(\mathrm{X})$ berpengaruh secara signifikan terhadap variabel Keputusan Pembelian (Y), maka Ha diterima dan Ho ditolak.

Terdapat hasil koefisien determinasi diperoleh $\mathrm{R}$ Square 0,262, dimana konstribusi varibel bauran promosi $(\mathrm{X})$ terhadap variabel keputusan pembelian (Y) adalah sebesar 26\% sementrara itu $74 \%$ ditentukan oleh faktor lain. Jadi hipotesisnya yaitu $\mathrm{Ha}$ diterima. Dengan demikian bauran promosi mempunyai konstribusi yang cukup besar dalam keputusan pembelian kamar di UNP Hotel \& Convention Padang.

Sebagaimana juga hasil penelitian yang telah dilakukan dapat dilihat bahwa diperoleh hasil koefisien regresi sebesar 0,928 yang artinya setiap peningkatan 1 satuan keputusan pembelian, dapat meningkatkan 0.928 satuan keputusan pembelian kamar, dapat diartikan bahwa baiknya bauran promosi dapat meningkatkan keputusan pembelian kamar. Komunikasi promosi yang baik akan dapat mempengaruhi konsumen untuk membeli suatu produk [9]. Untuk itu pihak UNP Hotel perlu memperhatikan promosi yang dilakukan karena memiliki kontribusi yang cukup besar dalam mempengaruhi keputusan konsumen.

\section{KESIMPULAN}

1) Variabel $X$ (Bauran Promosi) dari indikator yang sudah ditentukan menunjukkan secara keseluruhan dengan nilai persentase sebesar $45 \%$ berada pada $26,7-<33,3$ termasuk pada kategori kurang setuju.

2) Varibel Y (Keputusan Pembelian) dari indikator yang sudah ditentukan menunjukkan secara keseluruhan dengan nilai persentase sebesar $41 \%$ berada pada 40 - < 50 termasuk kategori kurang setuju.

3) Terdapat pengaruh signifikan antara bauran promosi terhadap keputusan pembelian sebesar $26 \%$ sedangkan $74 \%$ dipengaruhi oleh faktor lainnya. 


\section{DAFTAR PUSTAKA}

[1] Rukamah Ade Dan Djamudin. Analisis Pengaruh Strategi Bauran Promosi Terhadap Peningkatan Volume Penjualan Jurnal Manajemen Vol 4 No.4. 2013

[2] Setiadi, Nugroho J. Perilaku Konsumen. Cetakan 4. Edisi Revisi. Jakarta : Kencana. 2010

[3] Erdin, A., \& Kasmita, K. (2020). PENGARUH PROMOSI TERHADAP KEPUTUSAN MENGINAP DI HOTEL NEW D'DHAVE PADANG. JURNAL KAJIAN PARIWISATA DAN BISNIS PERHOTELAN, 1(2), 59-63. https://doi.org/10.24036/jkpbp.v1i2.7172

[4] Kotler, Philip dan Kevin Lane Keller. Marketing Management, 15th Edition, Pearson Education, Inc. 2016

[5] Y. Abrian, A. Adrian, and R. Surendra, "Analysis of Factors Affecting Guest Decision in Purchase of Room Service in Hotel 'Grand Inna Padang,", J. Bus. Hosp. Tour., vol. 5, no. 2, pp. 193-200, 2019, doi: http://dx.doi.org/10.22334/jbhost.v5i2.165.

[6] Sugiyono. Metode Penelitian Kombinasi (Mix Methods). Bandung : Alabeta 2015

[7] Simamora, Henry. Manajemen Sumber Daya Manusia, Yogyakarta : STIEY 2015

[8] Assauri, Sotjan. Manajemen Pemasaran : Dasar, Kosep, dan Strategi, Jakarta : PT Raja Grafindo Perseda. 2015

[9] Sri Wdyanti Hastuti, M., \& Anasrulloh, M. (2020). Pengaruh Promosi Terhadap Keputusan Pembelian. Jurnal Ilmiah Ecobuss, 8(2), 99-102. https://doi.org/10.51747/ecobuss.v8i2.622 